Artigos 


\section{Intencionalidade, Sentido e Autotranscendência: Viktor Frankl e a Fenomenologia}

\section{Intentionality, Meaning and Self-transcendence Viktor Frankl and The Phenomenology}

DOI:10.12957/ek.2019.38992

Prof. Dr. José Reinaldo F. Martins Filho

jreinaldomartins@gmail.com

Instituto de Filosofia e Teologia de Goiás [IFITEG]

Este trabalho pretende inserir-se no ponto de confluência entre filosofia e psicologia, estabelecendo o diálogo de ambas estas áreas por meio de dois significativos movimentos que marcaram o século XX. Em primeiro lugar, a fenomenologia, iniciada por Husserl e posteriormente desenvolvida por vários outros. Em segundo lugar, a psicologia de Viktor Frankl, cujo principal ponto distintivo põe em realce a questão do sentido e sua importância para a estruturação das consciências individual e coletiva. O texto procurará apontar pontos de aproximação entre fenomenologia e logoterapia, tendo como mote a insurgência de ambas estas reflexões como formas de combater o reducionismo cientificista que impregnava as ciências humanas na passagem do século XIX para o século XX, bem como imprimir a sua parcela de contribuição no resgate do que há de fundamental no ser humano, a saber: a sua capacidade de constituir um sentido. Para isso, se concentrará ao redor do conceito de intencionalidade, ponto fulcral para a fenomenologia, e explicitamente apontado por Frankl como tema para o desenvolvimento de seu discurso sobre a capacidade de autotranscendência do homem.

PALAVRAS-CHAVE
Intencionalidade. Sentido. Autotranscendência.

Fenomenologia. Logoterapia 
This work intends to insert itself at the point of convergence between philosophy and psychology, establishing the dialogue of both these areas through two significant movements that marked the twentieth century. In the first place, phenomenology, initiated by Husserl and later developed by several other philosophies. Secondly, the psychology of Viktor Frankl, whose main distinctive point highlights the question of meaning and its importance for the structuring of individual and collective consciousness. The text will try to point out points of approximation between phenomenology and logotherapy, taking as motto the insurgency of both these reflections as ways of combating the scientific reductionism that impregnated the human sciences in the passage from the nineteenth century to the twentieth century, as well as print their portion of contribution to the recovery of what is fundamental in the human being, namely: its capacity to make meaning. In order to do so, it will focus around the concept of intentionality, the focal point for phenomenology, and explicitly pointed out by Frankl as the theme for the development of his discourse on man's capacity for self-transcendence.

KEYWORDS
Intentionality. Meaning. Self-transcendence.

Phenomenology. Logotherapy 


\section{Influências confessadas}

O atual contexto social, marcado por crises das mais diversas ordens, tem nos forçado a buscar respostas em perspectivas complementares, oriundas de diferentes setores do conhecimento, como é o caso da psicologia, da filosofia ou da educação. Foi em vista disso que, a par de minhas investigações sobre a tradição fenomenológica, com especial acento para os trabalhos de Husserl e Heidegger ${ }^{1}$, despertei-me para a obra de Viktor Emil Frankl, conhecida como a terceira via psicoterapêutica de Viena. Inspirado, por um lado, em suas experiências pessoais, como psiquiatra e neurologista judeu, mantido prisioneiro em Auschwitz e Dachau nos anos obscuros da Segunda Guerra Mundial, e, por outro, nos influxos da fenomenologia e do existencialismo, escolas filosóficas que se desenvolveram posterior ou concomitantemente ao acontecimento dos regimes totalitários, como formas de constituir uma leitura inédita do fenômeno humano em sua capacidade de constituir um sentido, Frankl encontrou o seu caminho, ao mesmo tempo inédito e inusitado. Para além do debate empreendido pelo resgate da noção grega de logos, aberta em todas as suas possibilidades de interpretação, chamou-me a atenção a capacidade de articulação entre filosofia e psicologia ${ }^{2}$, tendo como base conceitos amplamente difundidos na seara da fenomenologia, entre os quais, a ideia de intencionalidade - interpretada por Frankl como autotranscendência: "um fenômeno antropológico fundamental" (FRANKL, 2016, p. 24).

De fato, tal intersecção parece ser possível a partir das várias confissões emanadas pelo próprio autor nas vezes em que menciona as leituras de que sua obra é tributária, entre as quais a fenomenologia ocupa um lugar de destaque. Igualmente, tomando conceitos nucleares da tradição fenomenológica aos quais recorrentemente a logoterapia faz referência, seja numa aberta aproximação com seu contexto originário, seja com leve alteração na sua compreensão - como ocorre com as noções que iremos expor a seguir. Além disso, o próprio conceito de fenomenologia elaborado por Frankl coaduna-se com o entendimento consolidado por esta área da filosofia desde Husserl, como quando afirma: "a fenomenologia é uma tentativa de descrição do modo como o ser humano entende a si próprio, do modo como ele próprio interpreta a própria existência, longe dos

1 Ver, por exemplo, o texto Heidegger leitor de Husserl: sob a sombra da fenomenologia, publicado junto ao volume 28 da revista Prometeus, em 2018 (cf. MARTINS FILHO, 2018).

2 E não somente a filosofia e a psicologia, já que a educação também se manifesta como um tema patente no trabalho desenvolvido pelo professor Frankl: "o papel da educação, mais que transmitir tradições e conhecimentos, deveria ser o de refinar a capacidade humana de encontrar sentidos únicos. A educação de hoje não pode reduzir-se à reprodução, unicamente, do percurso das tradições; deve, sim, encorajar e desenvolver a capacidade individual da tomada de decisões autênticas e independentes" (FRANKL, 2011, p. 84). 
padrões preconcebidos de explicação tais como são forjados no seio das hipóteses psicodinâmicas ou socioeconômicas" (FRANKL, 2011, p. 16). Mais que isso, levando em conta o que é desenvolvido por Heidegger nos $\S \S 7$ e 10 de Ser e Tempo, apenas a fenomenologia se apresentaria como método adequado para a interpretação da existência humana e do ser em sentido geral, distanciando-se das contribuições até então exaradas pela biologia, psicologia e/ou sociologia, cuja unidimencionalidade de suas abordagens reduziria o foco sobre as dimensões somática, psíquica ou social, respectivamente - fazendo do homem muito mais um refém que um ente de possibilidades: "a logoterapia retraduz o conhecimento elaborado pela fenomenologia, referente às possibilidades de encontrar um sentido, para a linguagem da pessoa simples e comum" (FRANKL, 2007, p. 91).

Aliás, em $A$ vontade de sentido, texto que tomaremos por principal referência neste ensaio, Frankl exprime que a fenomenologia constitui a escola de pensamento que mais propriamente pode inserir-se no horizonte da vida concreta, entendimento que novamente o aproxima da concepção heideggeriana - já que também Heidegger valeu-se da fenomenologia como modo de interpretação do homem na condição em que se encontra "antes de tudo e no mais das vezes", isto é, a cotidianidade (a vida fática). Diz Frankl (2011, p. 89): “o que precisamos fazer é nos voltar para o modo através do qual o homem comum, o homem da rua, experimenta os sentidos e os valores e traduzir tais experiências em linguagem científica. Um empreendimento dessa natureza, eu diria, é, precisamente, o que deveria ser levado a cabo por aquilo que chamamos de fenomenologia". A fenomenologia seria, então, a ponte entre a reflexão especializada e a realidade vivida.

Neste trabalho, tentaremos apontar pontos em comum entre as filosofias de Husserl e de Heidegger e a logoterapia, de Viktor Frankl. Em suma, partiremos da tentativa de superação do reducionismo cientificista - com alcance significativo sobre as ciências humanas no século $\mathrm{XX}$ - e culminaremos na eleição do conceito de intencionalidade, crucial para uma adequada compreensão do movimento fenomenológico desde sua origem até os seus posteriores desdobramentos, não apenas para a filosofia, mas para as demais áreas que se serviram destes conceitos - neste caso, a psicologia frankliana.

\section{Por um retorno ao que há de fundamental no humano}

Entre outros aspectos, podemos vislumbrar um primeiro contato entre o pensamento de Viktor Frankl e a fenomenologia partindo de sua reação aos chama- 
dos "reducionismos científicos", que assolaram as humanidades especialmente na passagem do século XIX para o século XX. Do mesmo modo como August Comte $^{3}$ ficou impressionado com as teses evolucionistas, amparando-se num modelo semelhante quando da elaboração de sua "ciência da sociedade" - sociologia - outros impactos puderam ser identificados, inclusive nos âmbitos da filosofia e da psicologia. É verdade que, caso tomemos o horizonte de surgimento desta última, logo perceberemos sua derivação de uma espécie de ciência experimental, tendo em Freud um dos maiores expoentes de afastamento. De fato, a tese do inconsciente mudaria o foco da psicologia (se é que assim poderíamos chamá-la), convertendo-a rumo a novos espaços de interesse, do comportamento, simplesmente explorado na perspectiva dos condicionamentos, para o desvendamento da realidade psíquica em sentido mais profundo, para a dinâmica construção de um sujeito a partir de múltiplos confrontos que se travam na esfera interior - tema patente da tradição ocidental desde os primeiros impulsos dados por Agostinho ${ }^{4}$ e a filosofia moderna. No entanto, segundo Frankl, também Freud não se manteve isento ao seu zeitgeist, frente ao que é possível dizer: “a psicanálise é - e permanecerá sendo - o fundamento indispensável de toda terapia, também das escolas que ainda virão e, como tal, deverá aceitar, contudo, a sina de constituir um fundamento, isto é, a de tornar-se invisível na medida em que a construção acima dela se levanta" (FRANKL, 2011, p. 19).

Antes de tudo, vale advertir que, em vista da psicanálise freudiana, Frankl estabelece uma reação de desconfiança. Isso porque, segundo the parece, ela teria se tornado sobremaneira reducionista, na medida em que transformou o homem em objeto unidimensional de análise, supervalorizando o papel da dimensão instintiva como definidora do ser humano. Para Frankl (2011, p. 20), Freud "acreditou que o homem poderia ser explicado por meio de uma teoria mecanicista e que seu psiquismo poderia ser curado por meio de técnicas”. Na verdade, a crítica frankliana não objetiva unicamente a psicanálise, mas o que ele mesmo considerou como as três principais correntes de psicoterapia de sua época, quais sejam: a própria psicanálise, à que já nos referimos, mas também a psicologia individual e a psicologia analítica, numa referência a Freud, Adler e Jung, respectivamente. Enquanto leituras reducionistas da realidade humana,

3 Segundo Comte (1978, p. 68), "a ciência matemática deve, pois constituir o verdadeiro ponto de partida de toda educação científica racional, seja geral, seja especial, o que explica o uso universal que se estabeleceu há muito a esse propósito, de uma maneira empírica embora não tenha primitivamente outra causa que sua idade relativa".

4 De acordo com o pensamento frankliano, mesmo a afirmação de Agostinho precisaria ser revista: Paráfrase de Agostinho: "isso porque transcender-se a si mesma é um constitutivo da existência humana. [...] poderíamos dizer que o coração do homem não descansa até que se encontre e se realize o sentido da vida" (FRANKL, 2011, p. 73). 
todas estas tendências parecem amparar-se no chamado psicologismo, tese que defende o primado do psiquismo como fonte de explicação da realidade humana. O reducionismo freudiano teria dado margem para a ênfase no que Frankl chamou de "vontade de prazer", que toma o prazer como meta da vida humana - num itinerário de constantes satisfações. O paradigma da inferioridade versus superioridade, conforme enfatizado por Adler, comporia a "vontade de poder", recorrendo, em primeiro lugar, ao princípio da "inferioridade orgânica". Além de estar atrelado a um fundamento biologicista da psique, Adler cometeria uma petitio principii, já que "não é uma instância pessoal, senão uma instância social que determinaria a atitude e a orientação do homem para a comunidade" (FRANKL, 2015, p. 37). Assim, ao mesmo tempo em que a exterioridade seria a causa da "inferioridade", seria também a sua fonte de solução. Por fim, a psicologia de Jung teria se afastado por demais das bases científicas a fim de lhe facultar o status quo de respeitabilidade por parte da academia, forjando-se numa espécie de religião ${ }^{5}$. A fim de se fugir de uma leitura reducionista, portanto, precisaríamos ir além e, mesmo, deixar de lado certos aspectos destas psicologias, o que fica claro na seguinte passagem de $O$ sofrimento de uma vida sem sentido, em que Frankl afirma: "espero que, no âmbito de minha exposição, se evidencie que o psicologismo dinâmico é uma das mais consideráveis fontes de perigos e erros presentes na atual psicoterapia. Muito menos conseguiram manter-se livre de todo psicologismo, ou atuar livremente sobre ele, os três clássicos da sistemática psicoterapêutica, Freud, Adler e Jung” (FRANKL, 2015, p. 33-34).

$\mathrm{Na}$ origem de todo conflito, Frankl identifica a supervalorização de um modelo mecanicista, do qual as humanidades apenas seriam libertas graças à influência do movimento fenomenológico e, mais especificamente, do existencialismo. Aqui não nos interessa defender a postura existencialista de um ou outro autor particularmente - isso na medida em que eles próprios já definiram as balizas de interpretação de suas filosofias para além, no caso de Sartre, e para aquém, no caso de Heidegger, do existencialismo enquanto movimento filosófico. Importa, contudo, o que já em Husserl transparecia como crítica ao academicismo reinante nas mais diversas escolas de pensamento do século XX, entre as quais os impulsos da filosofia moderna - responsável pela implementa-

5 Para Frankl, amargas palavras devem ser dirigidas à psicologia analítica, por ter se tornado uma religião: “os novos deuses seriam os arquétipos. Só com referência a eles se proporciona à vida um sentido. O derradeiro apoio metafísico do homem encontrar-se-ia, consequentemente, em si mesmo, e sua 'psique' seria algo assim como um moderno Monte Olimpo povoado de deuses e arquetípicos. A psicoterapia individual tornar-se-ia uma ação sagrada, e a psicologia, uma concepção de mundo" (FRANKL, 2015, p. 38). 
ção do mecanicismo ${ }^{6}$ - ainda mantinham hegemonia. Para Frankl, o pior desta leitura é que o "o caráter especificamente humano do homem é negligenciado, por exemplo, por aqueles psicólogos que aderem ao 'modelo da máquina' ou 'ao modelo do rato"' (FRANKL, 2011, p. 25). Mas não somente. Indo além do modelo das psicologias experimentalistas, Freud e Adler também submeteram suas psicoterapias à mesma lógica de fragmentação, monopolizando suas análises ao redor de matrizes como o instinto e as relações de poder. O homem, em sua multiplicidade de aspectos constitutivos, torna-se, então, restrito a um ou outro viés; também a dinâmica da vida passa a orientar-se por teorias que não partem da realidade concreta em vista de sua significação, mas forçam-na em função de um formato de análise previamente definido. Trata-se do perigo de se transformar o homem em coisa-humana, frente ao que Frankl argumenta: "eu diria que a reificação se tornou o pecado original da psicoterapia. Mas o ser humano não é uma coisa. Essa qualidade de não-coisa [no-thingness], mais do que a de nadidade [nothingness], é a lição a se aprender a partir do existencialismo" (FRANKL, 2011, p. 15).

Por esta passagem percebemos o quanto a logoterapia parece ser tributária dos movimentos filosóficos que influenciaram a segunda metade do século XX, marcando um novo paradigma de leitura da realidade humana, por sua vez distante de quaisquer humanismos - com o caráter restritivo implícito nestes conceitos - ou, o que seria pior e, segundo Frankl, a principal marca do reducionismo, igualmente livre do sub-humanismo. Ao tratar o ser humano é preciso resgatar o que constitui a sua humanidade, isto é, o que o eleva acima da previsibilidade da natureza ${ }^{7}$. Por isso, é preciso resgatar uma leitura que vá além do homem-

6 Cf. Frankl (2011, p. 72), “de acordo com certa definição, sentidos e valores nada mais são do que formações reativas e mecanismos de defesa. Quanto a mim, particularmente, eu não estaria disposto a viver pelas minhas formações reativas, muito menos a morrer em nome de meus mecanismos de defesa".

7 No célebre livro Em busca de sentido Frankl introduz um exemplo que se tornaria recorrente em uma série de outros seus escritos. Após explicitar a busca de sentido na perspectiva do sofrimento, introduz o exemplo da relação entre humano e animal, apontando para o limite deste em face da possibilidade de vislumbrar o que vai além do imediato, da instantaneidade. Vejamos o que segue: “[...] pouco depois passei para outra questão, dirigindo-me desta vez ao grupo inteiro. Perguntei se um macaco utilizado para produzir soro contra poliomielite e que, por esta razão, fosse picado vez após vez, jamais seria capaz de captar o sentido do seu sofrimento. O grupo o negou unanimemente; pois com sua inteligência limitada ele não poderia entrar no mundo dos seres humanos, ou seja, o único mundo no qual o seu sofrimento seria inteligível. Fui em frente com a seguinte pergunta: 'E como é com a pessoa humana? Vocês têm certeza de que o mundo humano é um ponto final na evolução do cosmo? Não é concebível que ainda haja outra dimensão possível, um mundo além do mundo humano? Um mundo em que a pergunta pelo sentido último do sofrimento humano encontraria uma resposta?"” (FRANKL, 2017, p. 141-142). Apesar de por este fragmento claramente sugerir a questão religiosa, neste momento interessa-nos a capacidade de autotranscender-se inerente ao humano, dado de sua distinção dos outros seres biológicos. 
-coisa ou do homem-máquina (aos quais também equivaleria o entendimento de um homem-instinto), dando margem para o reconhecimento da centelha espiritual presente no humano, como sujeito de liberdade e responsabilidade. É, pois, urgente resgatar o homem em sua humanidade, não como máquina a ser consertada. Também as relações deixam de se afirmar puramente em seu aspecto homeostático, isto é, de manutenção do equilíbrio orgânico - valendo-se dos outros como meios para a saciedade dos desejos - para dar lugar ao encontro: "não são duas mônadas, mas, sim, seres humanos que confrontam um ao outro com logos, isto é, com o sentido do seu ser" (FRANKL, 2011, p. 18).

Enfim, para Frankl, a capacidade humana de oferecer uma atitude diante dos fenômenos somáticos e psíquicos implica a "elevação a um outro nível e a abertura a uma nova dimensão, à dimensão dos fenômenos noéticos, ou dimensão noológica - em distinção à biológica ou psicológica. É nessa dimensão que os eventos tipicamente humanos devem ser localizados" (FRANKL, 2011, p. 28). Fala-se, então, de dimensão espiritual do homem, que de modo algum pode ser concebida como um fenômeno primário da religião. Espiritual aqui tem a ver com logos, conceito grego que remete ao sentido de potência humana em relação aos demais animais, presos como são às suas instâncias biológico-fisiológicas. O homem é aquele que pode elevar-se para além de seu próprio corpo, indo além dos maiores limites e adversidades. Diz Frankl (2011, p. 28), "no momento em que o homem reflete sobre si mesmo - ou, se for preciso, rejeita a si mesmo; quando quer que ele faça a si próprio de objeto - ou aponte objeções a si mesmo; no momento em que o homem manifesta sua consciência de si, ou quando quer que exiba seu ser consciente, aí, o ser humano atravessa a dimensão noológica". De fato, ser consciente pressupõe a exclusiva capacidade humana de elevar-se sobre si, de julgar e avaliar as próprias ações e a própria realidade. Tanto a filosofia quanto a psicologia, precisam, portanto, colocar-se num novo ponto de confluência, levando em conta o limite imposto pelos antigos reducionismos e propondo uma leitura do ser humano que vise à integração de diferentes instâncias e/ou capacidades: a espiritual, a somática, a psíquica, mas também a social, a cultural, a estética, entre tantas outras.

Curiosamente, Frankl e Husserl partilharam uma leitura semelhante acerca de sua época, cada um visando ao seu horizonte mais próximo - a psicologia ou a filosofia. Ambos, contudo, tocam o fato de o excesso de especialismos, advindo das teorias mecanicistas, ser responsável por esta leitura fragmentada do homem. Em 1931 Husserl reconheceria: 
[...] é certo que existem ainda Congressos filosóficos; os filósofos encontram-se aí, mas não as filosofias. $O$ que a estas falta é um espaço espiritual comum, onde possam tocar-se e fecundar-se mutuamente. A unidade é, talvez, melhor salvaguardada no interior de certas escolas ou tendências, mas este particularismo em si permite manter a nossa característica do estado geral da filosofia, pelo menos nos seus pontos essenciais (HUSSERL, 2001, p. 14 - grifos do autor).

Passados quase trintas anos, Frankl salientaria:

[...] vivemos em uma era de especialistas, e isso tem um preço. Eu definiria um especialista como alguém que não mais vê a floresta da verdade, optando por enxergar apenas as árvores dos fatos. [...] Os recortes que as diferentes ciências têm feito da realidade têm se tornado tão díspares, tão diferentes entre si, que tem se tornado cada vez mais difícil montar uma totalidade a partir desses recortes (FRANKL, 2011, p. 31).

Ambos, porquanto, perceberam a necessidade de uma reorientação em nossa leitura do ser humano e de suas relações, orientação que passasse a tomar a esfera da abertura, da intencionalidade ou, para nos mantermos fiéis à terminologia frankliana, ao espaço da constituição dos sentidos, isto é, à esfera espiritual do homem. Somos cônscios de que nossa época padece por falta de alimentar-se espiritualmente - e, repetimos, isso nada tem a ver com o espaço específico da religião. $\mathrm{O}$ espiritual, ao qual retornaremos neste texto, toca a capacidade de produção de sentido, sem a qual não há vitalidade que resista.

Ao que parece, perdemos o foco na universalidade em função de salvaguardar a totalidade. Esta, porém, constroi-se sobre o princípio da mesmidade, que mata as relações e empobrece o sujeito que as experiencia. A crença de que a ciência exerce um primado sobre a época atual está amparada num princípio equivocadamente unilateral. Nesse sentido, há muitos que insistem em afirmar que o homem "nada mais é" que um complexo mecanismo bioquímico, alimentado por um sistema de combustão que leva energia a computadores com prodigiosos recursos de armazenamento de informação, o cérebro. Ocorre que, como nos ensinou o professor Frankl, o homem é infinitamente superior a um com- 
putador. Disso extraímos que a ciência não poderá responder à pergunta sobre o homem valendo-se unicamente do modelo científico, da mesma metodologia aplicada aos fenômenos físicos e químicos - numa herança direta ao utópico entendimento escolástico-moderno de que a matemática é a autêntica linguagem do universo. O homem é superior à matemática, à química, à física, porque é capaz de simbolizar. Diz Frankl: "no campo da ciência, projeções não só são legítimas, mas também obrigatórias. A ciência não pode abranger a realidade na totalidade de seu caráter multidimensional. Logo, a metodologia científica deve tomar a realidade como se ela, de fato, fosse unidimensional. No entanto, o cientista deve reconhecer o espectro legítimo do saber que produz, evitando, assim, as ciladas do reducionismo" (FRANKL, 2011, p. 42). Ao contrário, ao conceberem o homem, filosofia e psicologia devem ir além deste reducionismo, valendo-se de um olhar integrador - ou como Frankl preferiu dizer: pondo em curso uma abordagem dinâmica. Apenas o reconhecimento deste mecanismo multiforme pode conduzir ao resgate do ser humano enquanto tal. É aí que a pergunta elaborada por Frankl, como segue, “como será possível preservar o caráter de unidade do homem em face do pluralismo da ciência, num momento em que esse pluralismo é o solo fértil sobre o qual o reducionismo floresce?" (FRANKL, 2011, p. 33), terá como resposta o que Tomás de Aquino colocou como unitas multiplex, isto é: unidade na multiplicidade.

\section{Intencionalidade, sentido e autotranscendência}

Em segundo lugar, encontramos no conceito de intencionalidade outra forte influência da fenomenologia sobre a abordagem humanístico-existencial elaborada por Viktor Frankl. Trata-se de um conceito fundamental tanto para a fenomenologia de Husserl, quanto para as demais filosofias que, posteriormente, tornaram-se autônomas. Para Husserl a intencionalidade é o principal traço constitutivo da consciência ${ }^{8}$. Noutras palavras, no contexto da fenomenologia, ao contrário do que se concebeu desde a filosofia moderna, a consciência apenas

8 Frankl pensa a consciência a partir da noção alemã Gewissen, isto é, uma consciência pessoal e moral: "costuma-se definir a consciência - 'geradora de responsabilidade' - como a capacidade que a inteligência humana tem de julgar acerca do valor moral dos próprios atos. $\mathrm{O}$ homem tende a perguntar-se, em cada situação concreta, qual é a forma de agir 'correta', o que deve 'fazer' aqui e agora; toda a sua ação é, portanto, uma resposta ao sentido que consiga captar naquela situação" (FRANKL, 2016, p. 37). O mesmo aparece em outra obra: "a consciência (Bewusstsein) torna-se acessível como um ser que é (Seiendes); à consciência moral (Gewissen), ao contrário, não um ser que é, mas um ser que ainda não é, ou seja, um ser que deveria ser (Sein-sollendes)" (FRANKL, 2007, p. 30). 
pode existir como pura intencionalidade, isto é, direcionamento para fora, como explosão em direção a uma realidade a partir da qual se preenche de sentido. A noção de intencionalidade, portanto, torna-se o ponto de distanciamento entre uma concepção de sujeito como mergulho para dentro do ego e o olhar que se abre ao além de si. Aliás, esta metáfora do olhar é bastante conhecida, tendo sido utilizada por Frankl na famosa entrevista dada a Roy Bonisteel, em 1977. ${ }^{9}$ Como aponta Frankl, o olho pode muito bem ilustrar o que pretendemos dizer sobre o movimento intencional. Um olho somente estará de acordo com sua função, cumprindo seu papel no todo orgânico do qual faz parte, caso seja capaz de esquecer-se de si mesmo e se voltar para fora. $\mathrm{O}$ olho saudável não vê a si mesmo, mas a realidade que, ao mesmo tempo, o envolve e se oferece como fonte de significação. Apenas o olho doente vê a si, como quando alguém é portador de catarata, ou outra doença ocular. De fato, entre as condições de existência do homem está a intencionalidade, também chamada de abertura ou de autotranscendência tanto por Frankl, como por outros autores da fenomenologia.

Para Husserl, "a palavra intencionalidade significa apenas esta particularidade intrínseca e geral que a consciência tem de ser consciência de qualquer coisa, de trazer, na sua qualidade de cogito, o seu cogitatum em si próprio" (HUSSERL, 2001, p. 48). Paralelamente a este pensamento, no texto intitulado Une idée fondamentale de la phénoménologie de Husserl, l'intentionnalité, Jean-Paul Sartre apresenta uma interessante definição do que significa o conceito de consciência em Husserl, bem como de seu caráter fundamental como intencionalidade: “a consciência não tem 'dentro'; ela não é nada senão o fora dela mesma e é essa recusa absoluta, essa recusa de ser substância que a constitui como uma consciência" (SARTRE, 2005, p. 106). E a isso completa: "essa necessidade para a consciência de existir como consciência de outra coisa que ela, Husserl nomeia de intencionalidade" (SARTRE, 2005, p. 106-107). É verdade que este conceito tomaria conotações diferentes nos distintos momentos da obra de Husserl. Em todos os casos, contudo, resta a interpretação de que se trata do traço basilar para a noção de consciência. Desde a filosofia moderna tem-se pensado uma noção de sujeito cujos traços elementares são a racionalidade, a autonomia, a consciência e a ipseidade. No entanto, a ênfase numa racionalidade de fundamento matemático fez com que se deixasse de lado a polissemia inerente à noção de logos, como era intuída desde os gregos. De fato, logos nunca significou uma única e estanque modalidade de o homem se portar no mundo. Amparada no ideal de "tudo pela razão, nada sem a razão", a filo-

9 Cuja tradução na íntegra está disponível em <https://www.logoterapia.com.br/conteudo. php?cod=artigos $>$. 
sofia moderna consolidou a noção de autonomia como uma ponte de distinção entre o universo da subjetividade e a objetividade, ao ponto de alguns pensadores considerarem toda a realidade como uma mera representação do sujeito ${ }^{10}$. A noção de consciência derivada desta compreensão enfatizou o traço agostiniano de um pensamento autorreflexivo, quer dizer, que se volta sobre si mesmo com a finalidade de obter a verdade. Tal itinerário não poderia ter conduzido a outro lugar que ao excessivo apreço pela identidade pessoal, em detrimento de instituições antes tidas como fonte de sentido social (a família, a comunidade, a sociedade). Pensar a intencionalidade como traço essencial da consciência, portanto, significa retirá-la desta lógica de imersão, apontando para a condição necessária da relação: relação com a objetividade e com os outros que passam a ser entendidos como fonte de confirmação ou infirmação da realidade.

Dito de outro modo, com a noção de intencionalidade Husserl romperia com a longa tradição dualista instituída desde a filosofia antiga, com traço mais marcante a partir do pensamento moderno (séculos XVII e XVIII). Na filosofia de Husserl, por exemplo, somente a partir da intencionalidade é possível pensar a relação entre $e u$ e outros $^{11}$, a concepção de tempo, conceitos como liberdade e responsabilidade e, por eles, a importância dos valores humanos. A intencionalidade, por isso, não diz respeito simplesmente à capacidade da consciência de ir além de si, mas da potencialidade disponível ao homem de elevar-se, quer dizer, autotranscender-se: "os seres humanos estão sempre transcendendo a si mesmos na direção de sentidos que constituem algo diferente deles mesmos, que são bem mais do que meras expressões deles mesmos, mais do que meras projeções de si. Sentidos são descobertos, não podem ser inventados" (FRANKL, 2011, p. 79). Isso nos faz pensar, por exemplo, a importância dada à figura do outro pela fenomenologia de Lévinas, a exploração da constituição corpórea realizada por Merleau-Ponty ou, mesmo, o desenvolvimento de uma

10 Sobre isso é preciso recordar que, para Frankl, a noção de autotranscendência, relativa à intencionalidade, não implica na anulação da relação sujeito e objeto, mas, ao contrário, na manutenção desta tensão. Diz ele: "sob o impacto do existencialismo, tem sido dada muita ênfase no que diz respeito à subjetividade do ser humano. Na verdade, trata-se de uma interpretação errônea do existencialismo. Os autores que pretendem ter superado a dicotomia entre sujeito e objeto parecem não estar cientes de que - como uma verdadeira análise fenomenológica revelaria -, fora do campo de tensão que se polariza no estabelecimento da relação sujeito e objeto, não há cognição, nem conhecimento possível" (FRANKL, 2011, p. 67-68).

11 Aqui, aliás, é possível estabelecer outro ponto de proximidade entre a noção fenomenológica de Frankl e a fenomenologia husserliana que, a partir de uma reflexão sobre a constituição de sentido, evoluiu rumo às suas considerações sobre a intersubjetividade. Note-se, a partir deste fragmento, como o lugar do outro também vai sendo desvelado pela logoterapia: "contudo, não podemos esquecer que, entre essas situações, há, também, aquelas com algo em comum, o que, consequentemente, nos leva a afirmar a existência de sentidos que são partilhados por seres humanos, transversalmente, nas sociedades e, até mais, ao longo da história" (FRANKL, 2011, p. 73). 
filosofia da existência, intuída por Heidegger e concretamente posta em curso por Sartre ${ }^{12}$ e outros. Inscrevendo-se nestas fileiras, Frankl é incisivo ao dizer: "a existência não só é intencional, como também é transcendente. A autotranscendência constitui a essência da existência. Ser humano é direcionado a algo que não si mesmo. Por trás desse caráter de outro [otherness] [...] também incide a alteridade do referente intencional ao que o comportamento humano se refere" (FRANKL, 2011, p. 67).

A respeito de Heidegger, por conseguinte, vale a pena mencionarmos outro aspecto que serviria de base para a logoterapia. Trata-se da noção de abertura. Para muitos dos que se dedicaram ao incremento da fenomenologia, a filosofia de Ser e Tempo consistiu numa tentativa de aplicar a intencionalidade à compreensão da existenciaridade do humano - não simplesmente da existência, mas das características desta existência. O homem, no contexto dessa filosofia, é tomado como existente num modo de vida cotidiano, movido por empreendimentos de manutenção da vida e de constituição de sentido. A intencionalidade deve, então, ser pensada como possibilidade libertadora, como menciona Lévinas (2000, p. 32) a respeito de Heidegger: "a intencionalidade animando o próprio existir e toda uma série de 'estados de alma' que, antes da fenomenologia heideggeriana, passavam por 'cegos', por simples conteúdos”. Entretanto, na medida em que se concentra na experiência cotidiana da existência, Heidegger deixa de lado o uso direto da expressão intencionalidade, substituindo-o por, ao menos, três outros conceitos que podem ser indicados como seus legítimos herdeiros, como segue: a abertura, a compreensão e a finitude. Abertura e compreensão são os modos fundamentais do ente humano. Abertura às múltiplas possibilidades de ser e compreensão do sentido de $\operatorname{ser}^{13}$. A finitude, por outro lado, delimita o horizonte temporal a partir do qual se realizam a abertura e a compreensão ${ }^{14}$. Na exploração de sua finitude o homem reconhece-se aberto a possibilidades concretas de $\operatorname{ser}^{15}$. A intencionalidade, disposta como abertura e

12 Ao falarmos de Sartre neste texto sempre devemos ter em conta as ressalvas impostas por Frankl. A teoria dos valores, emanada pela logoterapia, se "opõe ao argumento de Jean-Paul Sartre, que afirma que ideias e valores são esquematizados e inventados pelo homem" (FRANKL, 2011, p. 79).

13 Diz Frankl (2016, p. 27 - grifos do autor), "o ser humano, com efeito, necessita [...] de uma tensão fecunda entre dois polos: entre aquilo que ele é e aquilo que ele deve ser; necessita da tensão existencial entre o ser e um sentido que ainda está por realizar".

$14 \mathrm{Na}$ obra Um sentido para a vida: psicoterapia e humanismo, publicada no Brasil em 2005 pela editora Ideias e Letras, Frankl dedica todo um ensaio a esta temática, titulado "Temporalidade e mortalidade: um ensaio ontológico". Embora o mesmo tenha evidentes pontos de distanciamento em relação ao pensamento heideggeriano, há também intersecções possíveis de serem estabelecidas, especialmente em vista da compreensão do sentido da morte.

15 A relação entre morte e finitude, expressa pela filosofia heideggeriana, também compa- 
compreensão, torna possível a constituição de sentido e a autotranscendência como características eminentemente humanas, muito além de uma pura submissão ao nível instintivo. Aqui podemos nos lembrar do que Frankl afirma em $A$ vontade de sentido: "a qualidade essencial autotranscendente da existência confere ao homem a qualidade de um ser que se move numa busca para além de si mesmo" (FRANKL, 2011, p. 17-18 - grifos do autor).

$\mathrm{Na}$ esteira do que refletimos no tópico anterior, aqui encontramos o que, para Frankl, firma-se como possibilidade de ir além de quaisquer reducionismos, a constatação de que os fenômenos especificamente humanos são oriundos da condição intencional da consciência e de sua abertura ao além de si $^{16}$. Assim, outra excelente definição dada por Frankl ao homem é: "ser humano significa direcionar-se, como meta, a algo ou a alguém que não a si mesmo" (FRANKL, 2011, p. 36-37 - nota de rodapé). Entre outras questões, há aqui alguma proximidade entre o entendimento heideggeriano de abertura e o que Frankl elabora sobre o homem: "o homem é aberto ao mundo. Ele é o contraste com os animais, que não são abertos ao mundo (Welt), mas, sim, limitados a um meio (Umwelt) específico à espécie". Um pouco mais adiante a condição intencional da existência humana se explicita ainda mais, fazendo-nos incluir o pensamento frankliano definitivamente na esteira da tradição existencialista: "derrubar as barreiras do meio imposto à espécie Homo sapiens é uma característica constitutiva da existência humana. O homem busca - e, em sua busca, tende a atingir - o mundo, mundo esse repleto de outros seres humanos a encontrar e de sentidos a preencher" (FRANKL, 2011, p. 45). Esta mesma concepção talvez possa ser identificada na filosofia de Sartre ou de algum outro existencialista: o homem não é uma natureza posta a fim de se identificar a um modelo ou a um formulário pré-estabelecido, mas o que faz de si mesmo - no caso de Frankl: $a$ partir do sentido que encontra.

rece ao pensamento de Frankl: "a vida do ser humano é absolutamente singular: ninguém pode repeti-la - ninguém pode viver a vida de ninguém, em virtude do caráter de unicidade da existência humana. Cedo ou tarde, cada ser humano único morre, e, com sua morte, vão-se também todas as oportunidades irrepetíveis de realização de sentido" (FRANKL, 2011, p. 72-73). Relativamente à filosofia heideggeriana, pudemos explorar essa relação no texto Morte e finitude na filosofia de Martin Heidegger, publicado em 2016 no volume 13 da revista Griot (cf. MARTINS FILHO, 2016).

16 Sobre isso Frankl fala de abertura a partir de dois fenômenos humanos: o amor e a consciência - a partir dos quais podemos enxergar a influência da tradição fenomenológica de Husserl e Heidegger. Diz ele: "essas são as duas mais surpreendentes manifestações de outra capacidade exclusivamente humana, a capacidade de autotranscendência. $\mathrm{O}$ homem transcende a si mesmo tanto em direção a um outro ser humano, quanto em busca do sentido" (FRANKL, 2011, p. 29). A definição de consciência para Frankl aparece um pouco mais adiante nesta mesma obra: "[...] na busca pelo sentido, o ser humano é guiado por sua consciência. Esta pode ser definida como a capacidade intuitiva do homem para encontrar o sentido de uma situação, sentido esse que - sendo sempre único - não se submete a uma lei geral” (FRANKL, 2011, p. 82). 
Em busca de consolidar este entendimento, várias filosofias manifestaram a sua parcela de contribuição, entre as quais as de Sartre e Heidegger, que definiram o ser humano como existente, ou, mesmo, a de Hannah Arendt, quando se negou a conceber um tratado sobre a "natureza humana", substituindo-a pela "condição humana". Em todo caso, trata-se de pensar o homem em sua polissemia de sentidos e em sua capacidade de abrir-se à existência. Em cada circunstância, o homem põe em jogo o seu próprio ser, como único responsável ${ }^{17}$ pelo exercício de sua liberdade de escolhas, nos fazendo lembrar o que disse Heidegger no segundo parágrafo de Ser e Tempo: [o homem] "não é apenas um ente que ocorre entre outros entes. Ao contrário, ele se distingue onticamente pelo privilégio de, em seu ser, isto é, sendo, estar em jogo seu próprio ser" (HEIDEGGER, 2012, p. 48) ${ }^{18}$. Sentido é, por isso, “o que se tenciona [...]. O ser humano é responsável por dar a resposta certa para as perguntas, encontrando o verdadeiro sentido de uma situação" (FRANKL, 2011, p. 81 - grifos do autor).

Para Frankl, apenas "quando o homem preenche um sentido lá fora, no mundo, é que ele realizará a si mesmo. [...] a autorrealização é o efeito não intencional das intenções da vida. [...] O homem se torna o que é por força da causa que ele fez sua" (FRANKL, 2011, p. 53). Isso porque, "a cada momento a mente humana está direcionada por alguma intenção. [...] cada fenômeno psíquico se caracteriza pela referência a um conteúdo, pela direcionalidade a um objeto" (FRANKL, 2011, p. 55). Por isso, não será recolhendo-se em si mesmo que o homem conceberá algum sentido, mas na dedicação a uma causa, a alguém, na ressignificação de um sofrimento, de um acontecimento da vida, o que dá à logoterapia, muito além das demais psicoterapias mencionadas acima, um caráter teleológico altamente positivo. A intencionalidade, como força motriz da vida, visa o futuro como horizonte de materialização da existência - o processo de autoconhecimento, na insistência de passar a vida em revisão, não se aprisionará no passado, mas terá o futuro como meta a ser alcançada. Daí que se trate de uma psicoterapia teleológica e não remissiva, fatalista, refém do passado. A existência somente será autêntica quando reconhecer-se fundamentada sobre o sentido, sentido que, em todos os casos, sempre significará autotranscendência: "tenho tentado demonstrar que a existência vacila, hesita incerta, a menos que haja por trás dela, uma 'ideia forte', ou um sólido ideal” (FRANKL, 2011, p. 67).

17 Sobre responsabilidade, aliás, segundo Frankl (2011, p. 66), "trata-se de um conceito negativo, que demanda um complemento positivo. Este é a responsabilidade, que possui dois referentes intencionais. Pode significar um sentido por cuja realização somos responsáveis e, também, pode dizer respeito a um ser por quem somos responsáveis".

18 Quem sabe o mesmo significado do questionar-se, tal como exposto por Heidegger: Entre outras possibilidades, estamos falando do homem enquanto "ente que cada um de nós mesmos sempre somos e que, entre outras coisas, possui em seu ser a possibilidade de questionar" (HEIDEGGER, 2012, p. 43). 


\section{Filosofia e psicologia do sentido: em busca de sentido}

Certamente haveria muitos outros pontos de relação entre a tradição fenomenológica e o pensamento de Frankl, entre os quais, por exemplo, pensando em Heidegger apontaríamos a importância das disposições afetivas como condições fundamentais da existência humana, num claro distanciamento ao monopólio da razão, tal como defendido pela filosofia moderna. Isso se torna claro, entre outros episódios, no seguinte fragmento de Frankl (2011, p. 27): “o humor, também, é uma capacidade unicamente humana, e não devemos sentir vergonha de tal fato. Diz-se até que o humor constitui um atributo divino". Não obstante, apesar de tal intersecção poder se tornar mote para o desenvolvimento de ulteriores aproximações de nossa parte, neste momento apenas quisemos indicar a centralidade da noção de intencionalidade, própria à fenomenologia, como condicionante para se pensar a autotranscendência humana: "esta autotranscendência do existir humano consiste no fato essencial de o homem sempre 'apontar' para além de si próprio, na direção de alguma causa a que serve ou de alguma pessoa a quem ama. É somente na medida em que o ser humano se autotranscende que lhe é possível realizar-se - tornar-se real - a si próprio" (FRANKL, 2016, p. 24-25).

A respeito da fenomenologia, podemos considerá-la uma filosofia do sentido, dado que Husserl a intuiu, paralelamente ao seu incremento como uma filosofia do rigor, como um modo autêntico de compreendermos como se dá a constituição do sentido. De fato, a fenomenologia husserliana deve ser reconhecida como uma filosofia do sentido, tal como a logoterapia granjearia, no seio das vertentes psicoterapêuticas, o espaço de uma psicologia do sentido. Em ambos os casos estamos diante de respostas legítimas à época atual, de modo que sua validade permanece patente ainda entre nós. Se com a fenomenologia aprendemos que a esfera do sentido é anterior à do ser, ou, mais que isso, que o sentido implica diretamente sobre o modo de ser em curso, com Frankl renovamos esta compreensão: "eu diria que é propósito do sentido regular a marcha, o ritmo do ser" (FRANKL, 2011, p. 68). Ser e sentido formam, então, o jogo nuclear que continua a impulsionar filosofia e psicologia em seu anseio de moverem-se sempre mais longe: "o sentido é, pois, uma silhueta que se recorta contra o fundo da realidade. É uma possibilidade que se destaca luminosamente, e é também uma necessidade" (FRANKL, 2016, p. 35). 
COMTE, August. Curso de filosofia positiva. Discurso sobre o espírito positivo. Discurso preliminar sobre o conjunto do positivismo. Tradução de José Arthur Giannotti e Miguel Lemos. São Paulo: Abril Cultural, 1978.

FRANKL, Viktor E. Um sentido para a vida: psicoterapia e humanismo. Aparecida-SP: Ideias e Letras, 2005.

. A presença ignorada de Deus. Tradução de Walter O. Schlupp e Helga H. Reinhold. São Leopoldo: Sinodal; Petrópolis: Vozes, 2007.

A vontade de sentido: fundamentos e aplicações da logoterapia. Tradução de Ivo Studart Pereira. Edição ampliada incluindo o posfácio "A desfiguração da logoterapia". São Paulo: Paulus, 2011. - Coleção Logoterapia.

. Em busca de sentido: um psicólogo no campo de concentração. Tradução de Walter O. Schluppe e Carlos C. Aveline. São Leopoldo: Sinodal; Petrópolis: Vozes, 2017.

. O sofrimento de uma vida sem sentido: caminhos para encontrar a razão de viver. Tradução de Karleno Bocarro. São Paulo: É Realizações, 2015.

- Sede de sentido. Introdução, tradução e notas de Henrique Elfes. São Paulo: Quadrante, 2016. - Temas cristãos, 39.

HEIDEGGER, Martin. Sein und Zeit. Frankfurt am Main: Vittorio Klostermann, 1977. Gesamtausgabe: Band II. Abteilung: Veröffentlichte Schriften 1914-1970. Tradução brasileira, organização, nota prévia, anexos e notas de Fausto Castilho: Ser e Tempo. Campinas, SP: Editora Unicamp; Petrópolis, RJ: Editora Vozes, 2012.

HUSSERL, Edmund. Cartesianische Meditationen und Pariser Vorträge. Auf Grund des Nachlasses veröffentlicht vom Husserl-Archiv (Louvain) unter Leitung von H. L. van Breda. Martinus Nijhoff, 1973
[Husserliana I]. Tradução portuguesa de Maria Gorete Lopes e Sousa e introdução de Antônio Magalhães: "Meditações cartesianas: introdução à fenomenologia”. Porto: Rés, 2001.

LÉVINAS, Emmanuel. Ética e infinito: diálogos com Philippe Nemo. Tradução de João Gama. Lisboa: Edições 70, 2000.

MARTINS FILHO, J. R. F. "Heidegger leitor de Husserl: sob a sombra da fenomenologia”. In: Prometeus - Filosofia em Revista, vol. 28, Aracajú, 2018. pp. 105-117.

. "Morte e finitude na filosofia de Martin Heidegger: uma intuição de Sein und Zeit ao pensamento da história do ser". In: Griot-Revista de Filosofia, Amargosa, vol. 13, 2016. pp. 238-256.

SARTRE, Jean-Paul. Une idée fondamentale de la phénoménologie de Husserl: l'intentionnalité. Tradução de Ricardo Leon Lopes: "Uma ideia fundamental da fenomenologia de Husserl: a intencionalidade". In: Veredas FAVIP, Caruaru, vol. 2, n. 1, jan/jun, 2005. pp. 102-107.

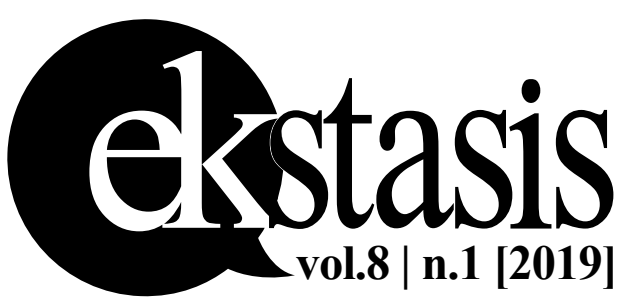

